IX International Scientific Symposium

"Farm Machinery and Processes Management in Sustainable Agriculture", Lublin, Poland, 2017

DOI: $10.24326 /$ fmpmsa.2017.14

\title{
SELECTED PHYSICAL PROPERTIES OF EXTRUDED FOAMED MATERIALS BASED ON STARCH
}

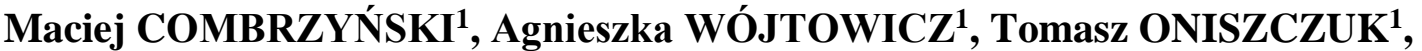 \\ Leszek MOŚCICKI ${ }^{1}$, Özge ÖZMEN ${ }^{2}$
}

${ }^{1}$ University of Life Sciences in Lublin, Department of Thermal Technology and Food Process Engineering, POLAND

${ }^{2}$ Mersin University, Gıda Mühendisliği Bölümü, Çiftlikköy Kampüsü, 33343, Mersin, TURKEY

E-mail of corresponding author: maciej.combrzynski@up.lublin.pl

Keywords: starch, foams, extrusion-cooking, physical properties, sustainability

\begin{abstract}
Starch-based foamed materials were processed with extrusion-cooking. Potato starch was used as a basic raw material. Plastronfoam PDE and poly(vinyl) alcohol were added in the amount of 1, 2, and 3\% of starch mass. Directly expanded foams were produced with the extrusion-cooking process at $80-110^{\circ} \mathrm{C}$ with $19 \%$ of initial moisture of blends. The processing was carried out at 100 and $130 \mathrm{rpm}$ with two types of forming dies: round and ring of 3 and $5 \mathrm{~mm}$ of internal diameter, respectively. The obtained foams were put to cutting test to evaluate the durability of samples expressed in the maximum force needed to break the sample. The increasing amount of additives had a different influence on the foams' hardness. Plastronfoam PDE lowered the cutting force of foams independently of the screw speed and forming die applied. An opposite trend was observed when poly(vinyl) alcohol was used as an additive. The samples shaped with the round forming die exhibited a higher hardness and better durability than the foams shaped with a ring die. The results could be helpful in management of optimum composition and treatment conditions to achieve desirable and sustainable products with desired properties.
\end{abstract}

\section{INTRODUCTION}

Polymer foams are polymers with bubble pores but are also known as materials with a reticulated structure (Mittal 2013; Pu et al. 2017; Zhang and Li 2000). Such foams are usually made from conventional polymers, such as polyethylene (PE), polypropylene (P), polystyrene (PS), polycarbonate (PC), hard poly(vinyl) chloride (PVC) with some foaming agents added as powders, liquids or gas (Peisheng and Guo-Feng 2014; Siva et al. 2017; $\mathrm{Wu}$ and $\mathrm{Xu} 2002$ ). Due to their cellular structure, foamed materials are very popular across industries, such as the building and construction, cooling and freezing, and, mostly, packaging industry. They are resistant to heat and cold and, most importantly, to mechanical damage. Foamed loose fillers, next to film and rigid forms, are widely used for packaging (Machade et al. 2017; Zhou et al. 2006). Due to the limited resources of petroleum and stricter environmental requirements, polymers, including foamed materials, need to be replaced by environmentally friendly composites with some addition of renewable plant materials (Bhatnagar and Hanna 1996; Bryśkiewicz et al. 2016; Wójtowicz et al. 2009; Zhang and Sun 2007). Intensive research has been going on for many years to find natural renewable raw materials for biopolymers as sustainable solution. Starch-based biopolymers have been found suitable for various applications, such as packaging materials and fillers, and are the prevailing group of biodegradable materials available on the market (Gáspár et al. 2005; Mitrus et al. 2009; Patel et al. 2005). There are many methods suitable for the processing of biopolymers and, among bioreactors, the extrusion and reactive extrusion can be applied. The extrusion of porous materials gives the material a specific two-phase structure based on plant polymer chains and gas where small gas bubbles are evenly distributed in the internal structure (Garbacz 
and Tor 2007, Gendron 2004; Peng et al. 2016). Plant starches (potato, maize, wheat, tapioca) are the most promising biopolymers as they fit various biodegradable thermoplastic material applications (Cunningham et al. 1991; Combrzyński et al. 2015; Mitrus and Moscicki 2014; Wang et al. 2005). Biopolymers, such as starch and cellulose, are suitable for composting and decomposition in the soil without generating any waste. So, these raw materials are sustainable both as renewable and environmentally friendly. Much effort has been taken to investigate the options of improvement of the physical, mechanical and functional properties of biopolymers aimed to find the proper quality of final products (Cha et al. 2001; Lui and Peng 2005; Mitrus et al. 2016). The aim of the study was to determine selected physical properties of extruded starch-based foamed materials processed using a single screw extrusion-cooker with the addition of selected functional components.

\section{MATERIALS AND METHODS}

Potato starch (purchased from PEPEES S.A., Łomża, Poland) was used as the basic raw material. Plastronfoam PDE and poly(vinyl) alcohol AP in the amount of 1-3\% were used as additives. The ready blends of potato starch and additives were moistened with a proper amount of water to reach the target blend moisture of $19 \%$. The extrusion-cooking process was performed with the single screw extruder TS-45 (Metalchem, Gliwice, Poland) with the configuration of $\mathrm{L} / \mathrm{D}=12: 1$ and the compression ratio of 3:1. The processing temperature ranged from 80 to $110^{\circ} \mathrm{C}$ and two screw speeds were used: 100 and $130 \mathrm{rpm}$. Two types of forming dies were applied as shapers: a round die with the diameter of $3 \mathrm{~mm}$ (M1) and a ring die with the internal diameter of $5 \mathrm{~mm}$ (M2). The produced samples were dried at $40^{\circ} \mathrm{C}$ for several hours to reach the final moisture content of $6 \%$ of snacks. A cutting test was used to evaluate the hardness of obtained foams. The universal testing machine Zwick BDO- FB0.5TH (Zwick GmbH \& Co., Ulm, Germany) was used according to the method proposed by Jin et al. (1995) with some minor modifications. A $20 \mathrm{~mm}$-long sample was cut on the testing table at an angle of $90^{\circ}$ with a cutting knife. The cutting force $\left(\mathrm{F}_{\max }\right)$ was measured with a Warner-Bratzler steel blade with the test speed of $8.33 \mathrm{~mm}^{-1}$; the initial force was set at $0.1 \mathrm{~N}$. Force-displacement curves were recorded and analyzed with the testXpertIIv3.3 software based on the data from 10 replications. Statistica (version 6.0, USA) was used for the analysis of the results.

\section{RESULTS AND DISCUSSION}

Some extrusion-cooking processing parameters, as the temperature, screw speed, feeding rate and the moisture content as well as the rheological characteristics of starch, have an effect on product density, expansion, and many other physical properties, including the hardness of foamed loose extrudates (Nabar and Narayan 2006). The measurement of resistance to break is one of the most important features of foamed materials because of their application as protective fillers for sensitive products. The additives used in the experiment revealed various durability qualities of the tested foams.

The effect of cutting force on starch-based foams processed, with the addition of Plastronfoam PDE, are presented in Fig. 1. An increased amount of this additive lowered the cutting force results independently of the screw speed and forming die applied. The samples processed with the application of a ring forming die demonstrated higher resistance to cutting than the samples shaped with a round die. The cutting force in the ring-shaped foams was at least twice as high as in the round-shaped samples (Fig. 1a). 
Significantly lower cutting force values were reported for foams with the addition of Plastronform PDE compared with the control samples processed without any additives.
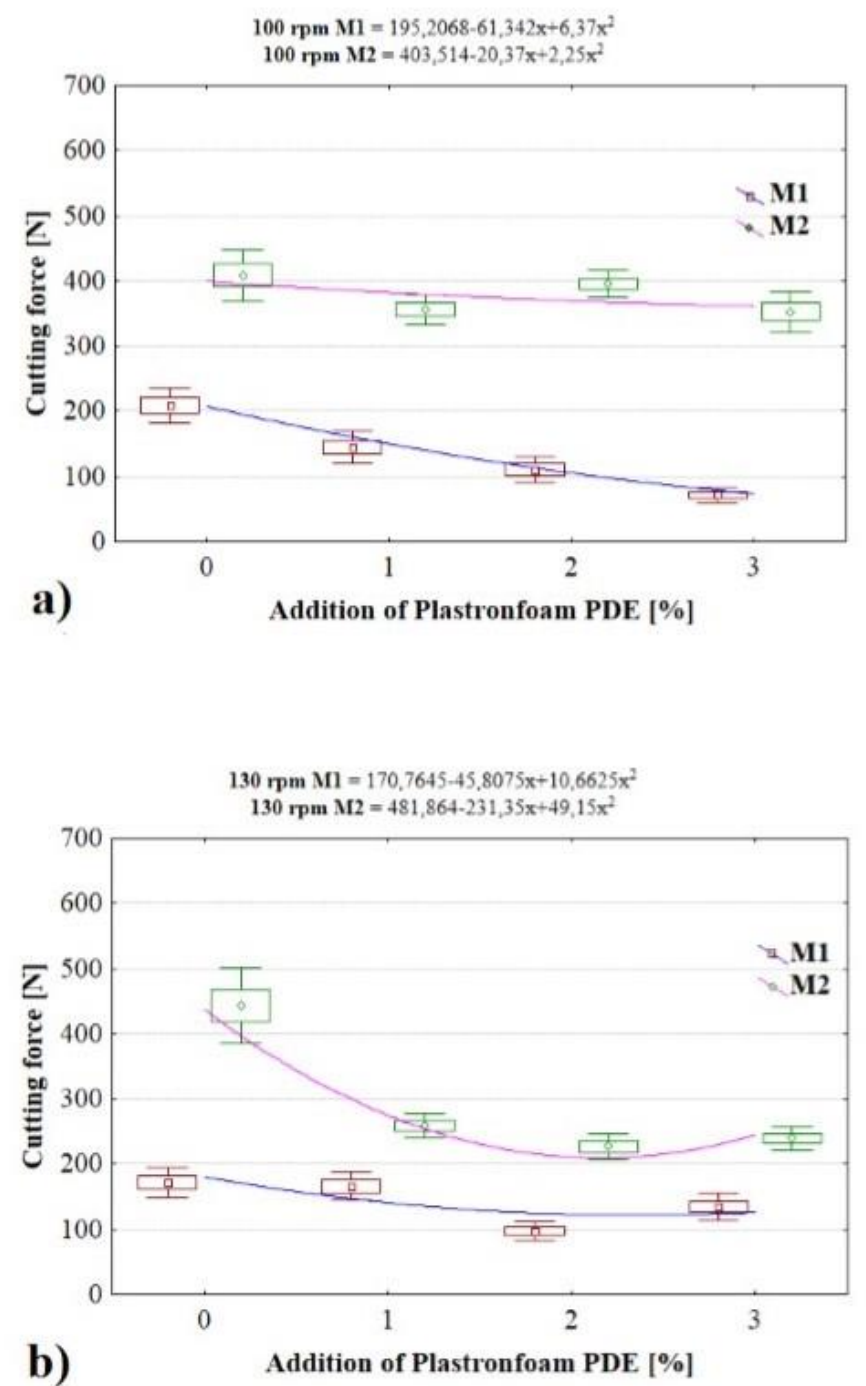

Fig. 1. The cutting force of starch-based foams processed with the addition of Plastronfoam PDE with various forming dies: a) $100 \mathrm{rpm}$, b) $130 \mathrm{rpm}$.

Correlation coefficients showed diverse dependencies depending on the shape of the forming die and the screw speed applied during processing. Fig. 1b shows the results of the applied cutting force on foams shaped at screw speed of $130 \mathrm{rpm}$ with round M1 and ring M2 forming dies. The highest correlation was observed when the M1 die was used and the processing screw speed was set at $100 \mathrm{rpm}(\mathrm{R} 2=0.994)$ and when the M2 forming die was used at the speed of $130 \mathrm{rpm}(\mathrm{R} 2=0.98)$.

A different trend was observed when poly(vinyl) alcohol was applied as an additive. An increased amount of the additive in blends raised the value of cutting forces (Fig. 2). Higher values of $F_{\max }$ were reported for samples processed with poly(vinyl) alcohol v. the control samples. Additionally, the shape of the forming die had a significant effect on the sample's hardness (Fig. 2a). A more rapid increase of hardness with the addition of poly(vinyl) alcohol was observed when the speed of $130 \mathrm{rpm}$ instead of $100 \mathrm{rpm}$ was applied during the processing (Fig. 2b), especially when the ring forming die was used for 
shaping. A significant effect on hardness ( $\left.\mathrm{p}_{\text {-value }}=0.000\right)$ was observed after the increasing of the quantity of poly(vinyl) alcohol coupled with positive correlation coefficients $\left(\mathrm{R}^{2}=0.999\right.$ and 0.992 , for M1 and M2, respectively) when processed at $100 \mathrm{rpm}$. Similarly, a positive effect was reported when the speed of $130 \mathrm{rpm}$ was applied during the processing with the correlation coefficients of 0.976 when shaped with the M1 die and 0.967 when the M2 ring die was used.

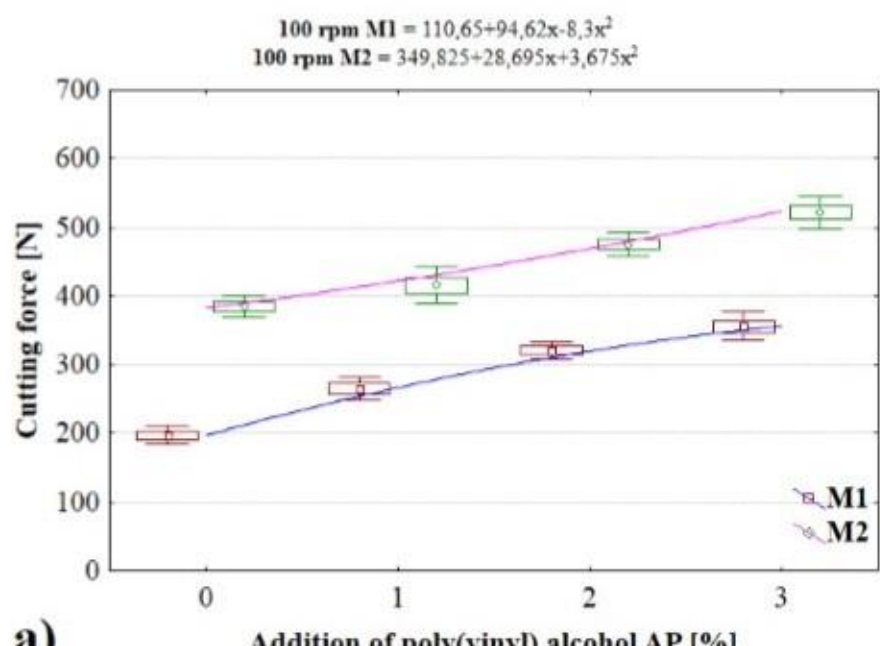

a)

Addition of poly(vinyl) alcohol AP [\%]

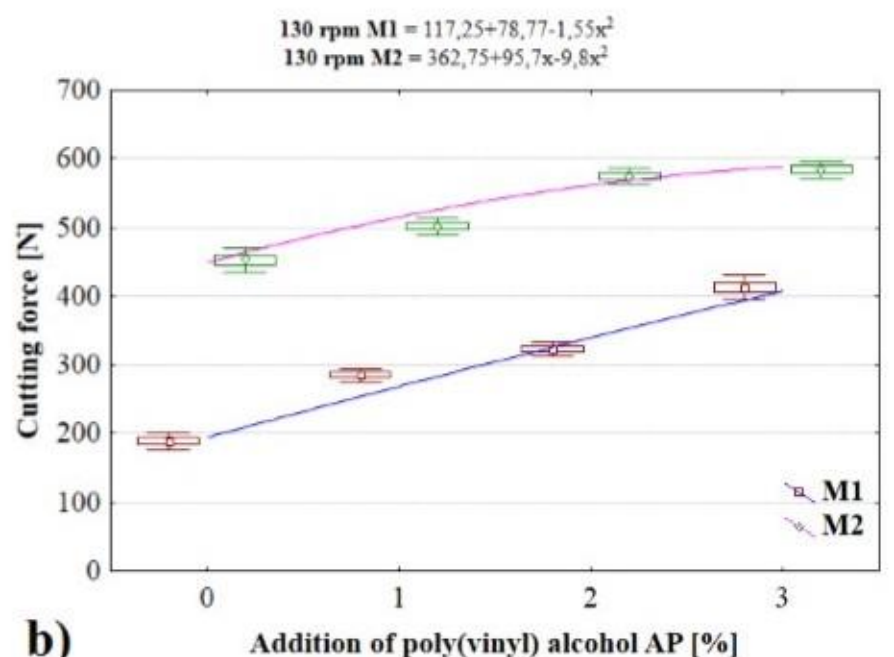

Fig. 2. The cutting force of starch-based foams processed with the addition of poly(vinyl) alcohol with various forming dies: a) $100 \mathrm{rpm}$, b) $130 \mathrm{rpm}$.

\section{CONCLUSIONS}

Potato starch with selected additives enables the production of foamed starch-based loose fill materials with different characteristics. The addition of Plastronfoam PDE lowered the maximum force needed to break the sample. An opposite trend was observed when poly(vinyl) alcohol was applied. The samples with this additive showed greater hardness and higher durability of foams as the amount of the additive was increasing. The results regarding the durability and resistance of foam to break can be useful in selecting the 
proper processing conditions to obtain starch-based biopolymer foams with the desired properties. Starch-based biopolymers could be a sustainable solution to waste management issues compared with conventional polymers which are becoming an environmental protection challenge. This makes the extrusion-cooking a suitable technique for the sustainable use of plant raw materials - among them environmentally friendly foam products.

\section{REFERENCES}

Bhatnagar, S., \& Hanna, M.A. (1996). Starch-based plastic foams from various starch sources. Cereal Chemistry, 73(5), 601-604.

Bryśkiewicz, A., Zieleniewska, M., Przyjemska, K., Chojnacki, P., \& Ryszkowska, J. (2016). Modification of flexible polyurethane foams by the addition of natural origin fillers. Polymer Degradation and Stability, 132, 32-40.

Cunningham, R.L., Carr, M.E., \& Bagley, E.B. (1991). Polyurethane foams extended with corn flour. Cereal Chemistry, 68, 258-261.

Combrzyński, M., Wójtowicz, A., Klimek, M., Mościcki, L., Oniszczuk, T., \& Juśko, S. (2015). Specific mechanical energy consumption of extrusion-cooking of wheat foamed packaging materials. Agricultural Engineering, 1(153), 25-34.

Garbacz, T., \& Tor, A. (2007). Wpływ zawartości środka porującego na właściwości użytkowe zewnętrznych powłok kabli wytwarzanych metodą wytłaczania porującego. Polimery, 52(4), 286-293.

Gáspár, M., Benkő, Z., Dogossy, G., Réczey, K., \& Czigány, T. (2005). Reducing water absorption in compostable starch-based plastics. Polymer Degradation and Stability, 90, 563-569.

Gendron, R. (2004). Thermoplastic Foam Processing: Principles and Development. CRC Press, Boca Raton, USA.

Machado, C.M., Benelli, P., \& Tessaro, I. C. (2017). Sesame cake incorporation on cassava starch foams for packaging use. Industrial Crops and Products, 102, 115-121.

Mitrus, M. (2012). Starch Protective Loose-Fill Foams. In: Thermoplastic Elastomers. El-Sonbati A.Z. (Ed.) InTech, Rijeka, Croatia, 79-94.

Mitrus, M., Combrzyński, M., Kupryaniuk, K., Wójtowicz, A., Oniszczuk, T., Kręcisz, M., Matysiak, A., Smurzyńska, A., \& Mościcki, L. (2016). Study of the solubility of biodegradable foams of thermoplastic starch. Journal of Ecological Engineering, 17(4), 184-189.

Mitrus, M., \& Moscicki, L.(2014). Extrusion-cooking of starch protective loose-fill foams. Chemical Engineering Research and Design, 92, 778-783.

Mitrus, M., Wójtowicz, A., \& Mościcki, L. (2009). Biodegradable polymers and their practical utility. In: Thermoplastic Starch. Janssen L.P.B.M., Moscicki L. (Eds), WILEY-VCH Verlag GmbH\& Co. KGaA, Weinheim, Germany.

Mitrus, M., Wójtowicz, A., Oniszczuk, T., Gondek, E., \& Mościcki, L. (2017). Effect of processing conditions on microstructure and pasting properties of extrusion-cooked starches. International Journal of Food Engineering, 13(6), DOI: 10.1515/ijfe-2016-0287.

Mittal, V. (2013). Polymer Nanocomposite Foams. CRC Press, Taylor \& Francis Group, LLC, Boca Raton, USA.

Patel, M., Bastioli, C., Marini, L., \& Würdinger, E. (2005). Life-cycle assessment of bio- based polymers and natural fiber composites. Biopolymers Online, 10, 1-59.

Peisheng, L., \& Guo-Feng, Ch. (2014). Porous Materials: Processing and Applications. Butterworth-Heinemann, Tsinghua University, China.

Peng, X. F., Liu, L.Y., Chen, B.Y., Mi, H.Y., \& Jing, X. (2016). A novel online visualization system for observing polymer extrusion foaming. Polymer Testing, 52, 225-233. 
Pu, W.F., Wei, P., Sun, L., Jin F.Y., \& Wang, S. (2017). Experimental investigation of viscoelastic polymers for stabilizing foam. Journal of Industrial and Engineering Chemistry, 47, 360-367.

Siva, M., Ramamurthy, K., \& Dhamodharan, R. (2017). Development of a green foaming agent and its performance evaluation. Cement and Concrete Composites, 80, 245-257.

Wójtowicz A., Janssen L.P.B.M., \& Mościcki L. (2009). Blends of natural and synthetic polymers. In: Thermoplastic Starch. Janssen L.P.B.M., Moscicki L. (Eds), WILEY-VCH Verlag GmbH\& Co. KGaA, Weinheim, Germany.

Wu, X.Y., \& Xu, J.Y. (2002). Polymer Foams Formation. China Petrochemical Press, Beijing, China.

Zhang, J.F., \& Sun, X. (2007). Biodegradable foams of poly(lactic acid)/starch I. Extrusion condition and cellular size distribution. Journal of Applied Polymer Science, 106(2), 857-862.

Zhang, Y. L., \& Li, C. D. (2000). Primary Introduction to Polymer Foams. Zhejiang Science And Technology Press, Hangzhou, China.

Zhou, J., Song, J., \& Parker, R. (2006). Structure and properties of starch-based foams prepared by microwave heating from extruded pellets. Carbohydrate Polymers, 63, 466-475. 